\title{
Implementation of Project Management Standards and Project Success: The Mediating Role of the Project Management Office
}

\author{
Amjad Pirotti ${ }^{1}$, F. A. Mohd Rahim ${ }^{2}$, and Norhanim Zakaria ${ }^{3}$ \\ ${ }^{1}$ Ph.D., Centre for Building, Construction \& Tropical Architecture (BuCTA), Faculty of Built Environment, University of \\ Malaya, Jalan Universiti, 50603 Kuala Lumpur, Wilayah Persekutuan, Malaysia, Email: amjadpirotti@gmail.com \\ (corresponding author). \\ ${ }^{2}$ Associate Prof., Centre for Building, Construction \& Tropical Architecture (BuCTA), Faculty of Built Environment, \\ University of Malaya, Jalan Universiti, 50603 Kuala Lumpur, Wilayah Persekutuan, Malaysia. E-mail: azli@um.edu.my \\ ${ }^{3}$ Senior Lecturer, Centre for Building, Construction \& Tropical Architecture (BuCTA), Faculty of Built Environment, \\ University of Malaya, Jalan Universiti, 50603 Kuala Lumpur, Wilayah Persekutuan, Malaysia. E-mail: \\ norhanimz@um.edu.my
}

\author{
Project Management \\ Received March 23, 2021; revised June 20, 2021; accepted June 25, 2021 \\ Available online September 15, 2021
}

\begin{abstract}
This research puts the spotlight on the implementation of project management standards, project management body of knowledge (PMBOK) 10 knowledge areas, in Iranian construction project-based organizations considering the significant role of the project management offices (PMOs) and to the extent to which that leads to project success. The objectives of this research are; to examine the influence of project management standards on project success, and to investigate the impact of PMO as a mediator between project management standards and project success in construction project-based organizations in Iran. Having the knowledge and research gap unfolded, a conceptual framework proposed to bridge the gap and three hypotheses were developed based on the study objectives. A survey, targeting Iranian project managers and construction practitioners working in grade 1 construction companies, was conducted and multivariate analysis techniques were adopted to analyze the data. After the exploratory and confirmatory factor analyses, the SEM analysis was used to test the hypothesized relationships. In general, the developed conceptual framework was confirmed, and the analysis enhanced the understanding of the current status of project management standard implementation and construction industry practitioners' perception of the factors contributing to project success.
\end{abstract}

Keywords: project management, project management standards, project management office, project success.

Copyright (C) Journal of Engineering, Project, and Production Management (EPPM-Journal).

DOI 10.32738/JEPPM-2022-0004

\section{Introduction}

The practice of project management (PM) has rapidly evolved over the years since it was formally introduced in 1957 (Kerzner, 2018). The theory of PM derives from different practices over years of managing projects. As such, this evolution goes across the method, guides, and standard documents for PM since it was first introduced in 1987 (Project Management Institute). Subsequently, the arrangement of the structure of the theory and practices of PM is derived from different organizations worldwide. The study of PM in terms of best practices has reinforced the idea that project management offices (PMOs) have a great value in the success of projects and PM (Archibald and Archibald, 2016). PMO has the capacity to maintain and develop a set of standards and methods, which becomes a steward of documented project management expertise inside the organization (Ogbu and Amade, 2017). Standards provided by PMO should be detailed enough to provide guidance but not up to the extent of details that might be a cause of creativity inhibition (Harrison and Lock, 2017). PMO is an organizational entity and it is established for managing a specific project or a series of related projects and all of these are handled by the project manager (Darling and Whitty, 2016), which is an organizational unit established for assisting project managers, functional entities throughout the organization for implementation of PM principles and assistance of teams at various management levels on the strategic basis (Biesenthal et al., 2019).

As opposed to the functional and matrix corporation, the project-based organization (PBO) has been suggested as a structure perfectly fitted for managing increasing product 
complexity, quickly evolving markets, cross-functional commercial expertise, customer centric innovation and market, and technological uncertainty (Hobday, 2000)." So far, however, there has been little research on the project management standards (PMS), the implementation of standards and methodologies within organizations and their relation to project success (PS), and the role of PMO in a PBO (Ahlemann et al., 2009), and it is expected that the attitude and perceptions toward the application of standards of project management may differ from one PMO to another as well as one country context to another (Jalal \& Koosha, 2015) This indicates a gap that practitioners and researchers are trying to fill which has continuously led to an expansion of PMS suited and tailored to specific contexts (Besner \& Hobbs, 2008). In spite of the fact that PMS furnish common portrayals of fundamental processes that are chosen and adopted to meet PBO's practices and culture, PBOs need to adapt to a number of elements and implement new frameworks and models to manage the projects (Aubry et al., 2010; Martinsuo et al., 2006; Pellegrinelli and Garagna, 2009). As authors so diverse as (Lewin, 1951; Luecke, 2003) described, these organizations can adopt many different paradigms and models for change. Such frameworks are, however, too generic (Gareis, 2010) and challenging to implement by project managers, who typically lack the specific skills required to manage the projects (Crawford and Nahmias, 2010). Nevertheless, there is a battle for many enterprises to identify the role of the PMO, to place the PMO for long-term success, and to exploit the PMO to help the success of the organization's strategic objectives. While no two PMOs are formed the same, it is evident that the function of the PMO is increasing in many organizations and there is a sturdy want to extend the PMO position to be more strategically centered by the improved scope of duty and collaboration with business leaders to achieve essential organizational objectives (Aubry et al., 2007).

In addition, although project management methodologies are naturally universalist, diverse contexts reflect different approaches to PM (Dahlman et al., 1987; Hanisch and Wald, 2012). PM is a subject of practice that promotes a normative method to the management of projects, and it is written in standards, tools and techniques, based primarily on practitioners' experience in western economies and depends appreciably on assumptions of economic rationality (Muriithi and Crawford, 2003). This issue emphasizes scrutinizing the implementation of the PMS within other regional contexts, in this case of Iran. Moreover, an overwhelming majority of the studies ignored to scrutinize the significance of PS through adopted standards in the organization considering the role of PMOs as the project management body of knowledge broker, and only a few research studies are conducted discussing the standards and methodologies within the organization, which presented the research gaps in the current study. (Ahlemann et al., 2009; Besner and Hobbs, 2008; Dahlman et al., 1987; Hanisch and Wald, 2012).

This research puts a spotlight on the implementation of PMS, in this study PMBOK 10 knowledge areas, within the Iranian construction context considering the significant role of the PMOs within PBOs and to the extent to which that leads to PS. This study investigates these objectives: to examine the influence of PMS factors on PS among construction organizations in Iran; and to investigate the impact of PMO as a mediator between PMS and PS in construction organizations in Iran.

\section{Conceptual Framework and Research Hypotheses}

Emphasizing the importance of PMS in the contemporary globalized world, with the coincidence of the emerging PBOs as well as the undeniable role of the PMOs as the project management body of knowledge brokers, it is proposed that PMS, formal documents that describe established norms, methods, processes and practices, are a crucial matter for the developing countries in which PM and PBOs are of ought most important part of every industry spheres. Concerning, the proposed theoretical framework (Fig.1) indicates the link between the implementation of PMS, in this study PMBOK 10 knowledge areas, and PS, necessitating examining the mediating role of the PMO within PBOs in construction organizations in Iran.

Success criteria focus on measures that are objectiveoriented, such as duration and time, quality, and cost (Pinto and Slevin, 1987). However, these objective measures have been criticized, particularly in the context of outlining complex PS (Ogunlana, 2010). Turner and Zolin (2012) have also suggested that success factors, unlike traditional factors (quality, time, and cost), can be measured before the project ends, which is beneficial in evaluating a project's success considering the long timeline for complex projects. In this study, Pinto and Slevin's (1987) study is employed emphasizing the same factors that were introduced by Jugdev and Müller (2005) as the most extensively used and recognized in measuring factors for success. Taking the lead from (Procaccino et al., 2005) and (Mazur et al., 2014), this study focuses on the three PS factors that are considered as "people related": (a) communication (b) project mission, and (c) top management support. These three factors have also been suggested as effective factors on PS particularly in construction PS in the most recent study (Pirotti et al., 2020).

The hypotheses of this study are as follows:

H1: It was hypothesized that PMO influences PS through effective communication, project mission and top management support among construction organizations in Iran.

H2: It was hypothesized that the implementation of PMS, PMBOK 10 knowledge areas, influences the success of project among construction organizations in Iran.

H3: It was hypothesized that PMO plays as a mediator between the implementation of PMS, PMBOK 10 knowledge areas, and PS among construction organizations in Iran.

Having the knowledge and research gap unfolded, a conceptual framework proposed to bridge the gap and three hypotheses were developed based on the study objectives. The research tended to put spotlight on, how PMO mediates the relationship between the implementation of PMS and PS within PBOs in other regional contexts, i.e. Iran, differs from the origin of the developed standard's country that remained opaque and untouched.

In the conceptual framework (Fig. 1.), regarding PMS factors, the framework outlined ten constructs: integration, scope, time, cost, quality, risk, human resources (HR), communications, procurement and stakeholder, the PMBOK 10 knowledge areas. Within the PS, the model proposed three constructs: communication, project mission 
and top management support. The PMO role element was represented by one construct: PMO.

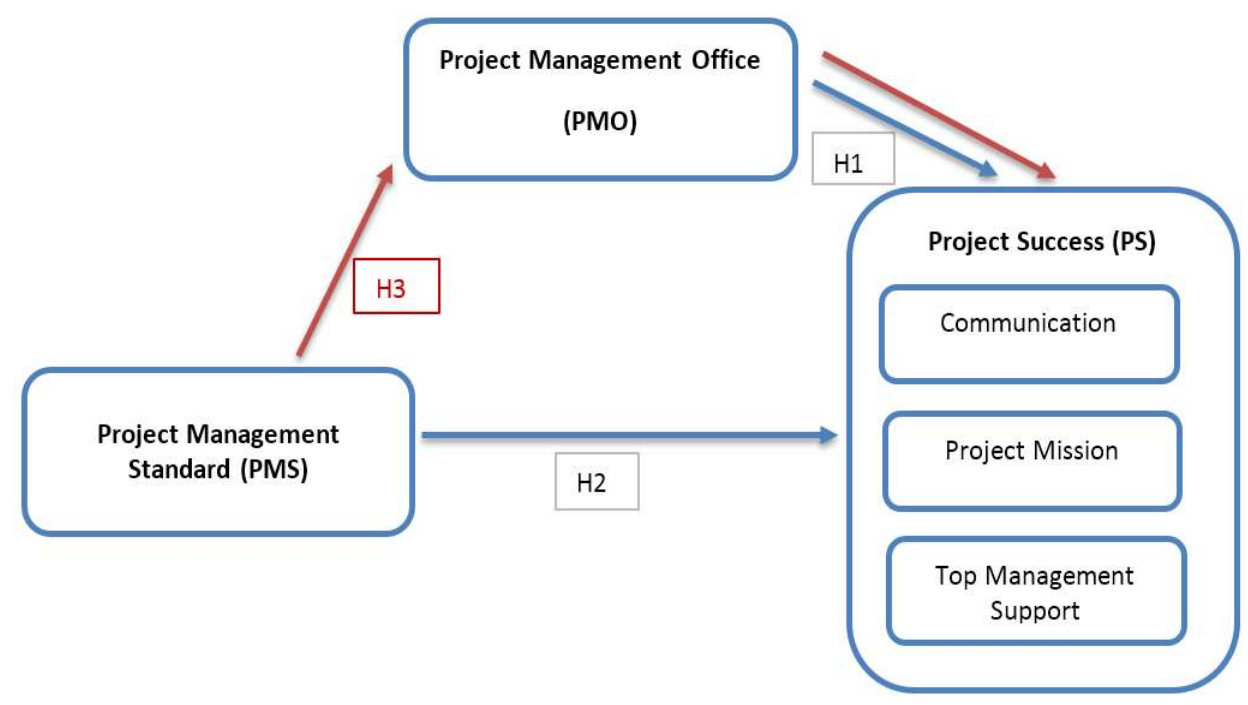

Fig. 1. Conceptual framework

\section{Research Methodology}

\subsection{Research Instruments}

This study employed quantitative methods and the distributed questionnaire consisted of four different sections. This research employed a single measurement scale avoiding responses contamination (Worthington and Whittaker, 2006) where items were all measured by a fivepoint Likert scale, which ranges from strongly disagree (1) to strongly agree (5). These measurement scales were considered suitable for the multivariate analysis techniques adopted in this study, including exploratory and confirmatory factor analysis, structural equation modeling (SEM), and correlation and regression analysis (Hair et al., 2006; Neuman, 2006). In order to avoid confusion and making sure that all respondents had a consistent definition of the PMO, the questionnaire's included a definition of PMO in its initial section. The first section of the questionnaire related to the demographic and general factors. The second section was dedicated to the PMO role factor construct. The third section covered the PMS constructs, and the fourth section of the questionnaire included PS constructs.

\subsection{Sampling and Data Collection}

As Neuman (2006) described sampling as a process of systematically choosing added cases for a research project. A researcher uses a set of cases that are more controllable and cost-efficient rather than using a pool of all the cases (Zikmund et al., 2010). A sampling element is the unit of analysis, or case, in a population. In this study, the unit of analysis was at the individual level; hence this study collected construction industry practitioners' perceptions who are registered under the Iran Construction Engineering Organization (IRCEO) and working in grade 1 construction companies as a member or manager of PMO. In total 650 questionnaires were distributed among construction practitioners working in grade 1 construction companies in Iran meeting two criteria, first, to be a certified member of IRCEO, and second, to be a member or manager of PMO in a project-based organization in a grade 1 construction company. Based on the formal classification, the construction companies in Iran are categorized into five grades in which grade 1 is the highest rank in terms of reputation and the largest volume of projects undertaken. According to a study by Jalal and kosha (2015), the total identified organizations, which have PMO as an entity were estimated to be nearly 50, as PMO is a new developing entity in Iranian organizations. Therefore only practitioners in grade 1 construction companies were targeted to collect the data where the probability of having PMO is much higher compared to other lower grades. In order to stay away from the possible bias of the collected data, no more than five legitimate questionnaires have been selected from each organization (Thiagarajan and Zairi, 1998). An adopted cross-sectional design was taken into account since it is the most common method to collect data as the aim of this quantitative study is to test the hypothetical relationships of the conceptual framework (Patterson and Williams, 2005). After the questionnaire was developed, a pilot survey was conducted in order to ensure that the respondents had no difficulty understanding the questions and to avoid any issues with the instrument's wording (Cavana et al., 2001). The pilot study involves 13 Iranian project managers, according to Nieswiadomy and Bailey (2017), obtaining approximately 10 participants for a pilot study is adequate. The 13 project managers represent construction industries in Iran, and their average experience in project management is +7 years. After the pilot survey, the final survey was developed and refined into an online questionnaire. One reason for using this method was to increase the speed and validity as well as eliminate the cost and time of printing and sending hard copy questionnaires through Iran's postal service. Secondly, one can easily transfer the online responses to the IBM SPSS database.

\subsection{Analysis}

Multivariate statistics are used to analyze the data obtained from the questionnaires, which is considered the best approach for the present study, with many independent and dependent variables (Tabachnick and Fidell, 2007). Descriptive data analysis was primarily employed using the SPSS (V.25) program to obtain a feel for the data and 
to determine if they met the basic assumptions required for executing multivariate data analyses. The analyses also included an evaluation of the profile of the respondents and data screening. The analysis of variance (ANOVA) was also conducted to ensure that the data was homogeneous across the different groups of respondents, and that it could be used to represent a single data set. Therefore, it is suitable for multivariate statistics for a single dataset based on a single questionnaire (Tabachnick and Fidell, 2007). A measurement scale, after descriptive analysis, was used in the questionnaire in order to seize each model construct's meaning and was assessed for validity and reliability. In addition, Cronbach's alpha was used to measure scale reliability which indicated the consistency of responses throughout items inside the scale. Moreover, item-total correlations were employed to investigate particularly the level to which an item belonged to its scale.

Due to the limited usage of measurement scales in the Iranian context, it was needed to verify their reliability for this research. Therefore, the measurement scale validity was investigated employing factor analysis in addition to examining reliability which was performed by using two sequential techniques: (1) exploratory factor analysis (EFA); and (2) confirmatory factor analysis (CFA). Factor analysis procedures are strong techniques in order to address a variety range of theoretical and managerial inquiries as these procedures define possible relationships in general form and then allow multivariate techniques to estimate relationships (Hair et al., 2006). Both EFA and CFA were carried out using SPSS.

After the establishment of reliability and validity of the measurement scales, the conceptual model was assessed. To evaluate the mediator in the model, SEM is employed (Jöreskog, 1993). This particular technique is selected for two good reasons. First, users are enabled by SEM to investigate both immediately assessed variables and latent. The utilization of latent variables eliminates the influences of unreliability inside mediator variables, as well as enhances the precision of the mediated impact measurement, thus, the latent variable strategy has a better statistical power to determine the mediating impact as opposed to the conventional regression analysis (Byrne, 2013). There are two steps involved in the SEM process: validating the measurement model; and fitting the structural model (Gerbing and Anderson, 1988). The former is achieved through confirmatory factor analysis, whilst the latter is achieved through path analysis with latent variables (Garson, 2012). In this study, AMOS (version 24) was employed since it was developed to operate on SPSS as an extension program. By using SEM, the confidence placed in the causal relationships, i.e., the internal validity of the model, was established. It was also possible to comprehensively assess these relationships by providing a transition from exploratory to confirmatory analysis. In addition, correlation analysis was employed, since the variables under research were quantitative, had five values, and were calculated on a level that at least approximates interval characteristics (Chen, 2007). For these reasons, the statistical technique of the Pearson product-moment correlation was first utilized to determine to the exact level which they were linearly related (Jaccard and Becker, 1997). This is followed by multiple regression analysis. As highlighted by Tabachnick and Fidell (2007), this is a strong technique employed in order to find out which specific independent variables predict the variance of dependent variables (Hair et al., 2006).

\section{Results}

\subsection{Description of the Sample}

A total of 250 usable responses were received, representing a response rate of $38.4 \%$, which according to Sekaran and Bougie (2016), is acceptable. The results showed that $45 \%$ of respondents are working as project managers, and many participants for this research were program managers and project coordinators, representing $22 \%$ and $10 \%$, respectively as depicted in figure 2 . A total of $50 \%$ of the respondents had reported an experience between 5 to 9 years within their organizations. A great number of grade 1 construction companies in Iran are public and the results of this survey revealed that $84 \%$ of respondents are working in public construction companies. Construction companies are traditionally male dominated and Iran construction companies are no exception which in this study males represent $78 \%$ of respondents while females accounting for $22 \%$.

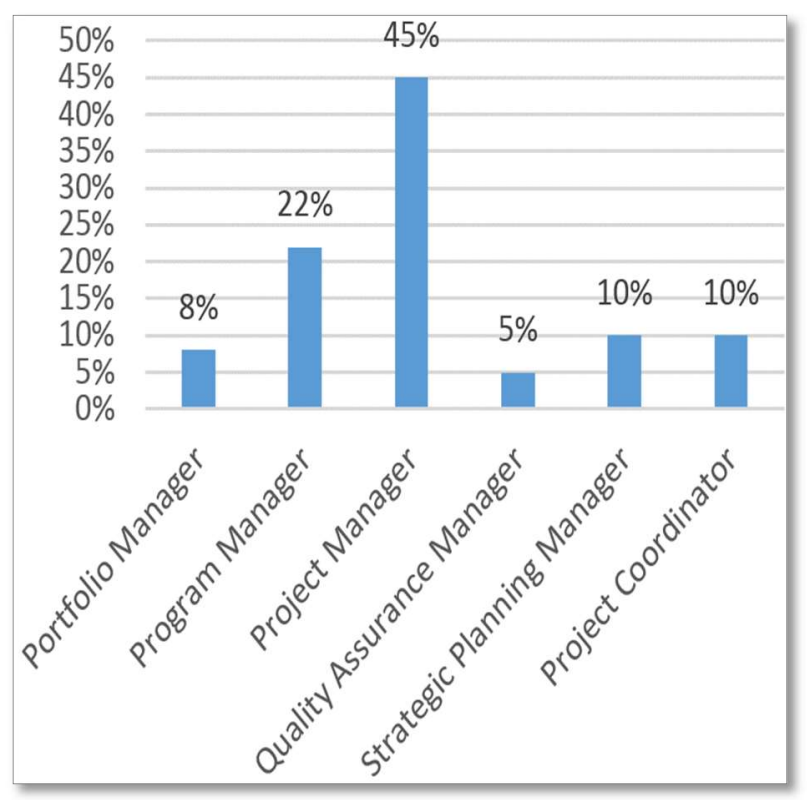

Fig. 2. Respondents' position distribution

\subsection{Structural Model Results}

The model exhibited a good level of fit $\left(\mathrm{X}^{2}=2619.64 ; \mathrm{df}\right.$ $=1205 ; \mathrm{X}^{2} / \mathrm{df}=2.234 ; \mathrm{GFI}=0.901 ; \mathrm{IFI}=0.917 ; \mathrm{TLI}=$ 0.895 ; CFI $=0.912$; and RMSEA $=0.070$ ). Six out of the twenty-one path coefficients were statistically not significant. As it is shown in Table 1, the PMS constructs (cost, procurement, communications, integration, scope, quality, and risk) had a positive influence on the PS construct as following: cost $(\beta=0.178)$, procurement $(\beta=$ $0.161)$, communications $(\beta=0.32)$, integration $(\beta=0.292)$, scope $(\beta=0.188)$, quality $(\beta=0.2)$ and risk $(\beta=0.24)$ while $\mathrm{HR}$, time and stakeholder were not significant. The findings show that there is a positive relationship between PMS and PS except for HR, time and stakeholder which supports H2.

Table 2 shows that PMO role construct had a positive influence on the PS construct $(\beta=0.319)$, thus supporting H1. 
Table 1. PMS and PS Relationship

\begin{tabular}{|c|c|c|c|}
\hline \multirow{2}{*}{ Hypothesis (path) } & $\begin{array}{c}\text { Standardized } \\
\text { estimate }\end{array}$ & \multirow{2}{*}{ CR } & \multirow{2}{*}{ Assessment } \\
\cline { 2 - 3 } & Beta $(\beta)$ & & \\
\hline H2_1:PS <-- HR & 0.165 & 1.896 & Rejected \\
\hline H2_2:PS <-- COS & 0.178 & $2.098^{*}$ & Supported \\
\hline H2_3:PS <-- PRO & 0.161 & $2.036^{*}$ & Supported \\
\hline H2_4:PS <-- COM & 0.32 & $3.662^{*}$ & Supported \\
\hline H2_5:PS <-- INT & 0.292 & $3.233^{*}$ & Supported \\
\hline H2_6:PS <-- SCO & 0.188 & $2.228^{*}$ & Supported \\
\hline H2_7:PS <-- TIM & 0.088 & 1.109 & Rejected \\
\hline H2_8:PS <-- QUL & 0.2 & $2.767^{*}$ & Supported \\
\hline H2_9:PS <-- RSK & 0.245 & $2.819^{*}$ & Supported \\
\hline H2_10:PS <-- SH & 0.109 & 1.471 & Rejected \\
\hline
\end{tabular}

Table 2. PMO and PS relationship

\begin{tabular}{|c|c|c|c|}
\hline \multirow{2}{*}{$\begin{array}{c}\text { Hypothesis } \\
\text { (path) }\end{array}$} & $\begin{array}{c}\text { Standardized } \\
\text { estimate }\end{array}$ & \multirow{2}{*}{ CR } & Assessment \\
\cline { 2 - 2 } & Beta $(\beta)$ & & \\
\hline H1:PS <-- -PMO & 0.319 & 2.639 & Supported \\
\hline
\end{tabular}

Sobel test which is the most common product-ofcoefficients test and assesses the presence of mediation by dividing the indirect effect (Fritz and MacKinnon, 2007), was calculated in order to detect whether the indirect relationship of PMS and PS through PMO was statistically significant. As a result is shown in table 3 , for the cost $(\beta=.192)$, procurement $(\beta=.144)$, communications $(\beta=.212)$, integration $(\beta=.183)$, quality $(\beta=.149)$ and risk $(\beta=.172)$, the indirect relationship was statistically significant while HR, scope, time, and stakeholder showed no significant results which supported the hypotheses H3_2, H3_3, H3_4, H3_5, H3_8 and H3_9." The final version of the tested conceptual framework developed the final model for this study which is shown in figure 3 .

Table 3. Sobel test results

\begin{tabular}{|c|c|c|c|c|}
\hline \multirow{2}{*}{ Factors } & Path A & Path B & Path C & \multirow{2}{*}{ Results } \\
\cline { 2 - 4 } & $\beta$ & $\beta$ & $\beta$ & \\
\hline HR & 0.121 & 0.165 & 0.1 & Rejected \\
\hline COS & 0.185 & 0.178 & 0.192 & Supported \\
\hline PRO & 0.127 & 0.161 & 0.144 & Supported \\
\hline COM & 0.104 & 0.32 & 0.212 & Supported \\
\hline INT & 0.075 & 0.292 & 0.183 & Supported \\
\hline SCO & 0.001 & 0.188 & 0.094 & Rejected \\
\hline TIM & 0.183 & 0.088 & 0.135 & Rejected \\
\hline QUL & 0.098 & 0.2 & 0.149 & Supported \\
\hline RSK & 0.1 & 0.245 & 0.172 & Supported \\
\hline SH & 0.279 & 0.109 & 0.194 & Rejected \\
\hline
\end{tabular}

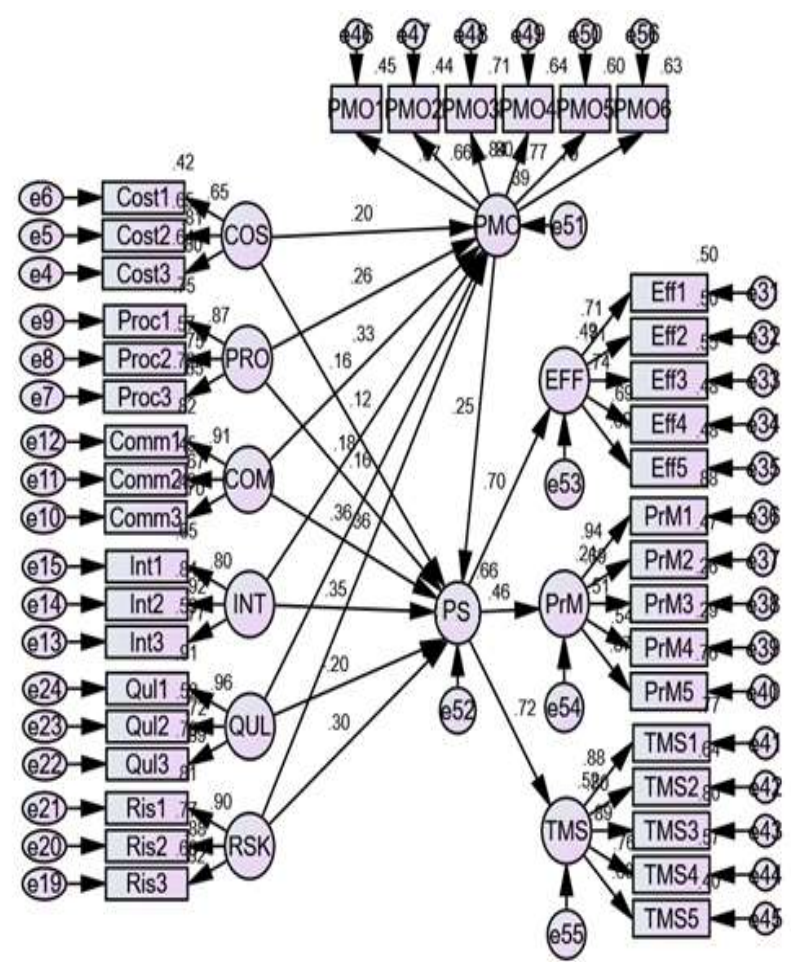

Fig. 3. Final model

\section{Discussion}

A number of researches have been conducted on the application and implementations of project management standards but they have not been able to streamline project standards and project success in a single study and to scrutinize the significance of project success through applied standards in the organization considering the role of PMOs as the project management body of knowledge broker. Generally, studies in western countries like Germany and Switzerland (Ahlemann et al., 2009) show that project management standards are not taken "as is" and are only partially applied and modified before any kind of implementation. Similarly, no two organizations can be aligned on the same project management standards due to the diversity of the standards to be implemented by various organizations and practitioners in different projects.

The initial conceptual framework, as depicted in figure 1 , led to the development of the conceptual model based on the comprising three main elements: 1) factors of PMS (PMBOK 10 knowledge areas) on project success; 2) PMO impact on PS; and 3) PMO mediation role between PMS and PS. Regarding PMS factors, ten constructs were proposed in the framework: integration, scope, time, cost, quality, risk, HR, communications, procurement and stakeholder, the PMBOK 10 knowledge areas. Within the PS, the model proposed three constructs: communication, project mission and top management support. The PMO role element was represented by one construct: Role of PMO. Three major hypotheses associated with the conceptual model were formulated and all fourteen constructs were executed in order to be accurately measured. Consequently, a set of measurement variables was developed to compute the model constructs. This study initially employed a quantitative-based questionnaire as the means for assessing the conceptual model. A robust questionnaire was developed based on a set of measures derived from the operationally defined constructs and was pre-tested in a pilot study. A survey targeting Iranian project managers and construction practitioners working in 
grade 1 construction companies was conducted. The results of the descriptive analysis revealed that the data obtained from 250 questionnaires adequately represented the survey population. The assessment of normality, standard deviations and standard errors of the means confirmed that the data was suitable for multivariate analyses. After the exploratory and confirmatory factor analyses, the study used an SEM analysis, which represented the relationship between constructs, to test the hypothesized relationships.

In general, the developed framework was validated, and the analysis enhanced the understanding of the current status of PMS implementation and project managers' and construction industry practitioners' perception of the factors contributing to PS within PMOs in construction projectbased organizations in Iran. However, the findings also show that some of the relationships were not significant. As per the finding of study seven (7) knowledge areas of PMS, namely; cost, procurement, communication, integration, scope, quality, and risk, had a positive influence on PS factor constructs while HR, time and stakeholder were not significant which showed that there is a positive relationship between PMS and PS except for HR, time and stakeholder which supported H2. The PMO role construct had a positive influence on the PS construct that supported H1. Finally, the indirect relationship of PMS and PS through PMO was statistically significant for cost, procurement, communications, integration, quality, and risk, while for HR, scope, time, and stakeholder showed no significant results. Based on the findings of this study the refined conceptual framework, figure 4 , is depicted and relationships are shown.

Construction projects in grade 1 companies in Iran are mainly defined and budgeted by the government and as we can see from the survey a large percentage (84\%) of respondents were from the public sector. It can be concluded that since the political considerations are the main determinative of the duration and budget of these projects and government bodies are the main stakeholders, this explains why some factors receive insufficient attention from project managers and construction industry practitioners. Generally, PM encourages the active participation of stakeholders in order to increases understanding of project risk and challenges, and to meet the stakeholders' expectations in controlling the cost, time and quality of the projects. Given the specific nature of the construction industry in Iran and political influences in government projects where government bodies are the main stakeholders and have direct decision-making influence over defining the projects, human resources, duration and financial performance of the projects, it can be explained why stakeholders management, time, HR and scope management is not perceived by project managers and construction practitioners as crucial as other factors (knowledge areas) contributing to project success in implementing PM tool and techniques and PM standard. Since the main characteristic of grade 1 construction companies in Iran is government ownership, it necessitates a change in government and regulatory bodies at the top management level towards supporting the decision making at a higher level in PMOs within construction organizations in Iran in order to facilitate achieving more mature PMOs in the construction industry in Iran.

This study contributes to both the body of knowledge in PM and practice. From a theoretical level the developed and tested conceptual framework contributes to the knowledge in the field of PM, and it is anticipated that by including PMO, as PM body of knowledge broker and mediator in the current study, it provides a framework through which current PMS implementation and practices in the construction industry in Iran is viewed and relationships between the variables assessed and interpreted.

From a practical aspect, the results of this study will help to explain those factors that are perceived by project managers and construction practitioners to contribute to PS and those that require to be paid more attention and to be taken into consideration for complete and whole PMS implementation in construction projects in Iran. Although the findings of this research are particular to the studied geographic area and specific industry, it can be significant to project-based organizations in different industries and regions.

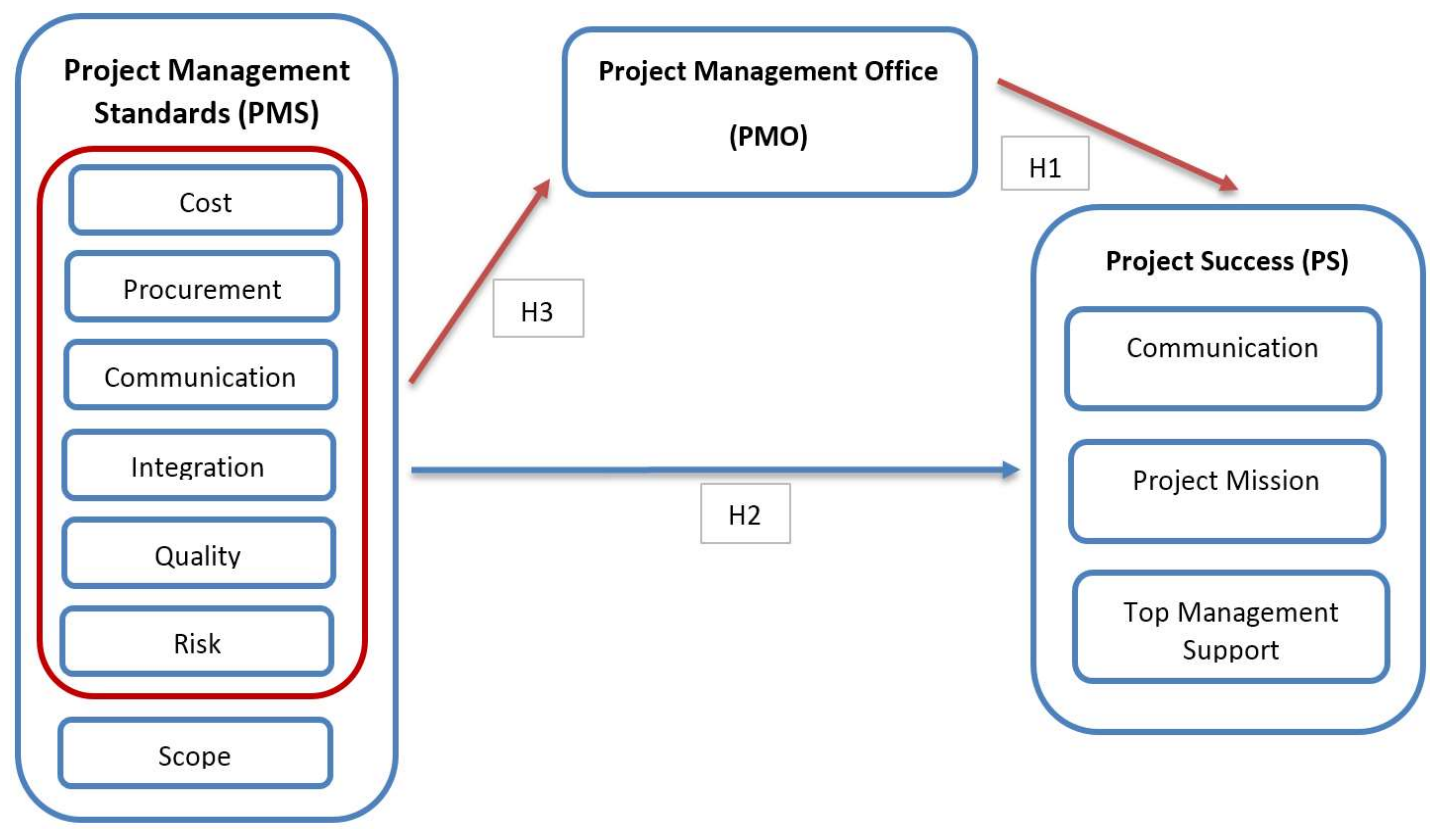

Fig. 4. Refined conceptual framework 


\section{Conclusion and Further Research}

The main goal of this research was to close the gap in the knowledge of PMS implementation and its contribution to PS considering the mediating role of PMO in the construction industry by testing the developed conceptual framework and the relationship between the variables. The developed model can be considered as decision support for authorities and regulatory bodies that how currently PM standard knowledge areas are seen and implemented by practitioners in achieving project success within PMOs and the results of this study would be crucial to enrich the body of knowledge in this area. Based on the results and analysis of this study it is concluded that PMO plays a mediator role between PM standard and project success. Further results revealed that PMO had a positive effect on PMS knowledge areas; integration, cost, quality, risk, communications, and procurement, except for HR, scope, time, and stakeholder in the construction industry in Iran. It is necessary to say that common PM standards can always be applied to all different projects and industries but it is the duty of the PMO to determine what standard/process with which level of management is needed for the project. In spite of the fact that PMS offers common portrayals of fundamental processes that are chosen and adopted to meet PBO's practices and culture, PBOs need to adapt to the number of elements and implement new frameworks and models to manage the projects.

Further studies can be conducted in other industries and regions where the applied and adopted PM standards are not of the origin of that country and that the attitude and perceptions toward application, and adoption of standards of PM might differ from one PMO to another. This study investigated the PMBOK 10 knowledge areas, as the most widely practiced and accepted standard, and its relationship to project success within PMOs. Further studies can explore other PM standards, tools and techniques that are applied by project managers in achieving high project performance and project success. In addition, PMO maturity level was not the scope of this study and therefore, further research and studies in the same area can be conducted considering PMO maturity level and to examine to what extend the PMO maturity contributes to the PM standard application and project success in organizational level.

\section{References}

Ahlemann, F., Teuteberg, F., and Vogelsang, K. (2009). Project management standards-Diffusion and application in Germany and Switzerland. International Journal of Project Management, 27(3), 292-303.

Aksözen, M., Hassler, U., Rivallain, M., and Kohler, N. (2017). Mortality analysis of an urban building stock. Building Research \& Information, 45(3), 259-277.

Archibald, R. D. and Archibald, S. (2016). Leading and Managing Innovation: What Every Executive Team Must Know about Project, Program, and Portfolio Management. CRC Press, Boca Raton, FL.

Aubry, M., Hobbs, B., and Thuillier, D. (2007). A new framework for understanding organisational project management through the PMO. International journal of project management, 25(4), 328-336.

Aubry, M., Müller, R., Hobbs, B., and Blomquist, T. (2010). Project management offices in transition. International Journal of Project Management, Vol. $28(8,766-778$.
Besner, C. and Hobbs, B. (2008). Project management practice, generic or contextual: A reality check. Project Management Journal, 39(1), 16-33.

Biesenthal, C., Gudergan, S., and Ambrosini, V. (2019). The role of ostensive and performative routine aspects in dynamic capability deployment at different organizational levels. Long Range Planning, 52(3), 350-365.

Byrne, Barbara M. (2010). Structural equation modeling with AMOS: basic concepts, applications, and programming (multivariate applications series), Taylor \& Francis Group, New York, NY.

Cavana, R., Delahaye, B., and Sekeran, U. (2001). Applied business research: Qualitative and quantitative methods, John Wiley \& Sons, Australia.

Chen, F. F. (2007). Sensitivity of goodness of fit indexes to lack of measurement invariance. Structural Equation Modeling: A Multidisciplinary Journal, 14(3), 464-504.

Crawford, L. and Nahmias, A. H. (2010). Competencies for managing change. International journal of project management, 28(4), 405-412.

Dahlman, C. J., Ross-Larson, B., and Westphal, L. E. (1987). Managing technological development: lessons from the newly industrializing countries. World development, 15(6), 759-775.

Darling, E. J. and Whitty, S. J. (2016). The project management office: it's just not what it used to be. International Journal of Managing Projects in Business, 9(2), 282-308.

Fritz, M. S. and MacKinnon, D. P. (2007). Required sample size to detect the mediated effect. Psychological science, 18(3), 233-239.

Gareis, R. (2010). Changes of organizations by projects. International Journal of Project Management, 28(4), 314-327.

Garson, G. D. (2012). Testing statistical assumptions. Statistical Associates Publishing, Asheboro, NC.

Gerbing, D. W. and Anderson, J. C. (1988). An Updated Paradigm for Scale Development Incorporating Unidimensionality and Its Assessment. Journal of Marketing Research, 25 No.2, 186-192.

Hair, J. F., Black, W. C., Babin, B. J., Anderson, R. E., and Tatham, R. L. (2006). Multivariate data analysis. Auflage, Upper Saddle River, NJ.

Hanisch, B. and Wald, A. (2012). A bibliometric view on the use of contingency theory in project management research. Project Management Journal, 43(3), 4-23.

Harrison, F. and Lock, D. (2017). Advanced project management: a structured approach. Routledge, London.

Hillson, D. and Murray-Webster, R. (2017). Understanding and managing risk attitude. Routledge, London.

Hobday, M. (2000). The project-based organisation: an ideal form for managing complex products and systems? Research policy, 29(7), 871-893.

Jaccard, J. and Becker, M. A. (1997). Statistics for the Behavioral Sciences. Brooks, Pacific Grove, CA.

Jalal, M. P. and Koosha, S. M. (2015). Identifying organizational variables affecting project management office characteristics and analyzing their correlations in the Iranian project-oriented organizations of the construction industry. International Journal of Project Management, 33(2), 458-466.

Jöreskog, K. G. (1993). Testing structural equation models. Sage Publications, Newbury Park, CA.

Jugdev, K. and Müller, R. (2005). A retrospective look at our evolving understanding of project success. Project management journal, 36(4), 19-31. 
Kerzner, H. (2018). Project management best practices: Achieving global excellence. John Wiley \& Sons, Hoboken, New Jersey.

Lewin, K. (1951). Field theory in social science: selected theoretical papers. Harper \& Brothers, New York, NY.

Luecke, R. (2003). Managing change and transition. Harvard Business Publishing, Boston, MA.

Martinsuo, M., Hensman, N., Artto, K., Kujala, J., and Jaafari, A. (2006). Project-based management as an organizational innovation: Drivers, changes, and benefits of adopting project-based management. Project Management Journal, 37(3), 87-97.

Mazur, A., Pisarski, A., Chang, A., and Ashkanasy, N. M. (2014). Rating defence major project success: The role of personal attributes and stakeholder relationships. International Journal of Project Management, 32(6), 944-957.

Muriithi, N. and Crawford, L. (2003). Approaches to project management in Africa: implications for international development projects. International journal of project management, 21(5), 309-319.

Neuman, W. L. (2006). Workbook for Neumann Social research methods: qualitative and quantitative approaches. Allyn \& Bacon, Boston, MA.

Nieswiadomy, R. M. and Bailey, C. (2017). Foundations of nursing research. Pearson, New York, NY.

Noe, R. A., Hollenbeck, J. R., Gerhart, B., and Wright, P. M. (2017). Human resource management: Gaining a competitive advantage. McGraw-Hill Education, NY.

Ogbu, J. and Amade, B. (2017). A Nexus between Project Management Offices (PMOs) and the Value of Project Management Performance of Public Tertiary Institutions in Nigeria. PM World Journal, 6(2), 1-24.

Ogunlana, S. O. (2010). Beyond the 'iron triangle': Stakeholder perception of key performance indicators (KPIs) for largescale public sector development projects. International journal of project management, 28(3), 228-236.

Patterson, M. E. and Williams, D. R. (2005). Maintaining research traditions on place: Diversity of thought and scientific progress. Journal of environmental psychology, 25(4), 361-380.

Pellegrinelli, S. and Garagna, L. (2009). Towards a conceptualisation of PMOs as agents and subjects of change and renewal. International Journal of Project Management, 27(7), 649-656.

Pinto, J. K. and Slevin, D. P. (1987). Critical factors in successful project implementation. IEEE transactions on engineering management, 34(1), 22-27.

Pirotti, A., Keshavarzsaleh, A., Rahim, F. A. M., and Zakaria, N. (2020). Effective Factors on Project Success in Malaysian Construction Industry. Journal of Engineering, Project, and Production Management, 10(1), 1-10.

Project Management Institute (2017). A Guide to the Project Management Body of Knowledge (PMBOK® GUIDE). Project Management Institute, Newtown Square, Pennsylvania.

Procaccino, J. D., Verner, J. M., Shelfer, K. M., and Gefen, D. (2005). What do software practitioners really think about project success: an exploratory study. Journal of Systems and Software, 78(2), 194-203.

Sekaran, U. and Bougie, R. (2016). Research methods for business: A skill building approach. John Wiley \& Sons, Chichester, United Kingdom.

Tabachnick, B. G., Fidell, L. S., and Ullman, J. B. (2007). Using multivariate statistics. Pearson, Boston, MA.

Thiagarajan, T. and Zairi, M. (1998). An empirical analysis of critical factors of TQM: A proposed tool for selfassessment and benchmarking purposes.
Benchmarking for Quality Management \& Technology, 5(4), 291-303.

Turner, R. and Zolin, R. (2012). Forecasting success on large projects: developing reliable scales to predict multiple perspectives by multiple stakeholders over multiple time frames. Project Management Journal, 43(5), 87-99.

Worthington, R. L. and Whittaker, T. A. (2006). Scale Development Research: A Content Analysis and Recommendations for Best Practices. The Counseling Psychologist, 34(6), 806-838.

Zikmund, W. G. babin, B. J., Carr, J. C., and Griffin, M. (2010). Business research methods. South Western Cengage Learning, Canada.

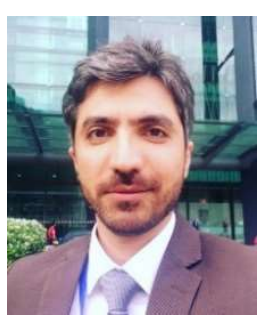

Amjad Pirotti holds a Ph.D. in project management and has many years of cross-industry experience with a proven track record in project management, demonstrating a portfolio varying in scope and complexity in a range of sectors, including consultancy, education, IT, and construction. Apart from industry exposure, he also has a wealth of experience in academia collaborating with higher education institutions, developed master's degree programs in blockchain and IoT, and authored books and articles in different areas, including project management, business, blockchain, and cyber security.

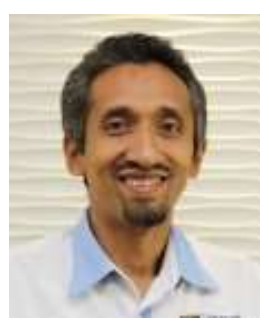

Associate Professor Sr. Dr. Faizul Azli Mohd Rahim is at the Department of Quantity Surveying, Faculty of Built Environment, University of Malaya, Kuala Lumpur. He graduated with BSc (Hons) Quantity Surveying from the University of Salford, UK in 1997 , and received M.Sc. IT in Property \& Construction from the same university in 1998. He graduated with a PhD from the University of Liverpool in 2011 in the area of project risk management. Since his appointment at the University of Malaya, he had been teaching various subjects such as data analysis, construction economics, project management and IT in construction. He is a registered quantity surveyor with the Board of Quantity Surveyors Malaysia (BQSM).

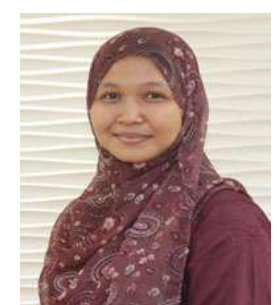

Dr. Norhanim Zakaria holds the Bachelor of Quantity Surveying from UTM. She attained her Master of Science in Construction Management from Universiti Teknologi Malaysia in the year 2000 and Doctoral degree in Project Management from UTM in 2011. She is now persuading her research interest in project management and construction economics. She was awarded the 'UM Excellent Award' in 2013 and has worked as a Principal Investigator and as a coresearcher for external and internal grants. Dr. Norhanim is a registered provisional quantity surveyor of the Board of Quantity Surveyors Malaysia. 